Eva Ciuk

Trieste

\title{
ISABEL ALLENDE O LA MORFOLOGÍA DE LAS VOCES FEMENINAS
}

Leer obras de la escritora chilena Isabel Allende es como escuchar una composición musical polifónica. Voces que han permanecido ignoradas por los compositores de la gran sinfonia latinoamericana salen del silencio para cantar y contar en voz alta lo que la historiografia y la cultura oficial no les ha permitido expresar. Son voces del silencio, voces de las víctimas del rígido sistema patriarcal, víctimas de la violencia y de la brutalidad del régimen dictatorial y voces de los marginados, postergados y excluidos de una colectividad conformista y artificial. En cambio las voces escogidas por la escritora para cantar la melodia principal son las femeninas, voces que en el contexto latinoamericano podian desahogarse sólo en el ámbito cerrado del hogar doméstico. Isabel Allende transforma las mujeres que permanecieron excluidas del gran acontecer histórico, de la vida cotidiana, social, cultural y política de su proprio país en las grandes protagonistas de su obra literaria. La dimensión de la mujer latinoamericana que ha sido relegada al silencio y al olvido, a la pasividad, a la subordinación y resignación emerge aquí con una energía vital y transgresora que transforma las protagonistas en figuras determinadas y subversivas que reclaman para ellas una transformación y mejoramiento de sus condiciones de existencia.

La forma más alta y completa en la que se expresa la fuerza y la rebeldia femenina surge de la personalidad subversiva de Eva Luna, la protagonista de la homónima novela que se publica en 1987. Eva Luna es la excluída absoluta, una mujer de origen marginal que se enfrenta al sistema autoritario que la oprime para vencerlo. La suya es la historia de una huérfana y sirvienta que se convierte al final de la novela en una triunfante autora de folletines televisivos. La historia de su vida nos permite relacionar la novela con las estructuras de la tradición picaresca que en este caso refleja las circunstancias histórico-sociales latinoamericanas contemporáneas. Eva Luna es la pícara del siglo veinte, una mujer que como todos los picaros lleva una vida de peregrinaciones, sufriendo explotación y humiliación. Isabel Allende renueva y adapta a sus propias exigencias algunas de las caracteristicas de la tradición picaresca, manifestando con esta novela una profunda reacción feminista a las limitaciones que el género picaresco impone al personaje femenino. Eva Luna se salvará de la existencia sórdida fundada en el engaño, astucia y violencia típicas del pícaro desarrollando al interno de la decadencia, mediocridad, hipocresia, violencia y corrupción de la sociedad latinoamericana un fuerte sentido crítico. Eva representa asi una pícara leal, sentimental, humanizada y luchadora (Gálvez-Carlisle 1991: 127) que no adquiere sólo una conciencia espiritual y emotiva sino también social y política.

Otro elemento, y tal vez el más importante, que hace de Eva Luna un símbolo de la reacción de la mujer a las limitaciones impuestas por el dispotismo patriarcal y machista latinoamericano es su total apropriación del poder del pícaro de ser él mismo el que cuenta en forma autobiográfica su propia vida. Esto ofrece a Eva Luna la posibilidad de excluir de su vida 
cada elemento de control y construir la realidad y su destino siguiendo sus propios deseos y exigencias. No hay un sujeto masculino que describe desde afuera el mundo de la mujer y su desarrollo emotivo y sentimental proyectando de esta manera una imagen de la mujer que mu-chas veces no corresponde a la realidad; una versión de la dimensión de lo femenino estereotipada e iconográfica presentada y perpetuada por la tradición literaria falocéntrica. Eva Luna cuenta su vida en forma autobiográfica hasta convertirse al final en en una de las protagonistas del folletín televisivo que está escribiendo. Eva-narradora y Eva-personaje se funden al final de la novela en la misma figura, confundiendo de esa manera al lector que tiene dificuldades en definir la frontera que separa la vida real y el folletín televisivo - la reescritura de la vida de Eva Luna. La protagonista reescribe su vida en la novela titulada Bolero, nombre que metafóricamente sugiere el sentido de la circularidad del tiempo y de la vida, diciendo "Cuando escribo cuento la vida como a mí me gustaria que fuera” (Allende 1987: 280). Eva excluye así cada elemento de control, convención o imposición desde el mundo exterior y construye la realidad en la que vivirá siguiendo sus propios deseos y exigencias. La reacción feminista de Isabel Allende se presenta así en la transgresión de las leyes del género picaresco y sobre todo superando la lógica del lenguaje falocéntrico: se produce en este sentido una literatura femenina alternativa ${ }^{1}$ en la que la mujer sale de la condición apartada y subordinada y reivindica el derecho a ser sujeto del discurso que, hasta entonces, se ha ido enunciando casi en su contra. Eva Luna toma conciencia de su identidad y demuestra al final de la novela haber logrado una cierta maduración espiritual diciendo que finalmente tiene: "el poder de determinar mi fin o inventarme una vida" (Allende 1987: 236). Marcelo Coddou escribe de Eva Luna: "Al componer su ficción ésta la crea a ella misma: la auto-afirma." (Rojas \& Rehbein 1991: 141) Lo que hace Eva escribiendo se acerca al efecto que tuvo el acto de escribir el "cuaderno de anotar la vida" a Clara en $L a$ casa de los espiritus (1982): el diario representa un espacio en el que se libera la voz femenina que nos permite entrar en el mundo interior de la mujer y recorrer al flujo de conciencia como estrategia discursiva para crear una literatura introspectiva, en la que escribir de sí mismas es un acto de búsqueda y descubrimiento de la propia personalidad.

Hablar de la autodefinición de la propia identidad y de la transgresión de Eva Luna supone hacer referencia a la progresiva toma de conciencia y al desarrollo sociológico gradual de las protagonistas de las novelas anteriores de Isabel Allende. Eva Luna se nos presenta así como el punto más alto de una espiral que empieza a alargarse y completarse partiendo de la figura de Clara, el personaje central de la saga familiar La casa de los espiritus. Presentando el mundo de la mujer de inicio siglo y pasando por un sendero ascendente iluminado de los nombres que viven en una dimensión luminosa (Nívea, Clara, Blanca, Alba), reflejo metafórico de la evolución que se produce en las conciencias de estos personajes tanto en el nivel personal y privado como en su progresiva participación en la historia, la escritora crea al final de la novela la última heredera de la necesidad de libertad e independencia que se transmite de generación a

1 Llamo literatura femenina alternativa porque en las novelas de formación latinoamericanas anteriores a la de Isabel Allende el viaje hacia la madurez de las protagonistas femeninas se tornaban en un fracaso total o muerte. No encontramos en este género de literatura protagonistas enérgicas y determinadas o luchadoras concientes, sino figuras resignadas o subordinadas que tarde o temprano aceptan las imposiciones del sistema familiar patriarcal. 
generación a través de la línea materna; es la guardiana de los secretos y de las locuras de la familia entera, la figura que representa la cumbre de la evolución de la mujer hacia la definición de su propia identidad. Se trata de Alba que haber transgredido las imposiciones del sistema familiar patriarcal y haber sufrido la violencia del régimen dictatorial, escribe la historia de su familia, en la que incluye la experiencia y el sufrimiento de todos los que estaban destinados a sobrevivir en la sombra. De esa manera Alba rescata del silencio no sólo la existencia de las mujeres de su familia, sino también el mundo de la mujer latinoamericana. Alba transgrede a través de la práctica del discurso el concepto mismo de la historia, insertando en ella también la historia de la mujer y su lucha contra el poder hegemónico.

Lo que hacen la más joven de la familia Trueba y Eva Luna inscribiendo la propia presencia en la historia lo hacen también todas las protagonistas de la narrativa de Isabel Allende. Todas las figuras femeninas dejan una huella profunda en la sociedad que las excluye. Cada mujer tiene su propia forma de expresar su personalidad e inscribir de alguna manera su presencia en la historia. Las que tienen suerte de poder aprovechar de una formación intelectual lo hacen escribiendo, como por ejemplo Clara compilando un diario, Alba escribiendo la historia de su familia y de su país, Irene en De amor y de sombra (1984) documentando el descubrimiento de unos cuerpos de los desaparecidos, Eva Luna con su folletín y en Hija de la fortuna (1998) Eliza en su correspondencia epistolar con Rose que escribe a su vez novelas eróticas. La educación y la curiosidad cultural representan para la escritora chilena uno de los medios más importantes en la emancipación y mejoramiento de la condición de la mujer latinoamericana.

Hay también otras formas de expresión a través de las que los personajes femeninos dan a conocer su propia historia, sus emociones, sentimientos y conflictos interiores. Se trata de medios de comunicación que metafóricamente pueden referirse al acto del escribir: son los rituales que la mujer cumple cotidianamente al interior del espacio concedido por el sistema familiar patriarcal. Estos actos adquieren en las novelas de Isabel Allende una valencia artística y se transforman en medios de comunicación con el mundo exterior del cual la mujer ha sido excluída. En La casa de los espiritus Rosa la Bella, un personaje casi mágico y celestial, está bordando animales y figuras mitológicas en el mantel más grande del mundo, Blanca moldea la arcilla, Alba pinta en la pared de su habitación sus estados anímicos y en El plan infinito (1991) Carmen alcanza éxito diseñando joyas étnicas.

A diferencia de las protagonistas de la novelistica anterior a la de Isabel Allende estas mujeres transgreden las normas del silencio imponiendo valores más auténticos y construyéndose una dimensión propia real y no más artificial y destinada al fracaso; un mundo independiente en el que la libertad y la sensibilidad de la mujer supera la brutalidad y la racionalidad del padre autoritario, del marido posesivo y también de la sociedad violenta y represiva. Todas, también las que pertenecen a las clases burguesa o medio-alta, son seres marginales, porque difieren por su originalidad del modelo impuesto por el código comportamental patriarcal. Su espíritu líbre huye del control del hombre racional.

Una de las figuras más originales que anticipa algunos de los aspectos fundamentales de Eva Luna, su natural predisposición a la fantasía y a la narrativa, es Clara en La casa de los espiritus. Tras la primera violencia subida por mano del marido violento y autoritario, Clara 
se defiende cerrándose en un largo silencio, definido por el marido una verdadera virtud de la mujer. En cambio será este silencio que impedirá a su marido controlar la evolución de la conciencia de su mujer que gracias a su natural predisposición a la imaginación y a la intuición se construirá un espacio que no corresponderá al orden impuesto por la ley del hombre. Clara encuentra refugio en una dimensión mágica y espiritual, dominada por las leyes que ella misma impone, las del amor incondicionado y materno, de la sensibilidad, de la aceptación, libertad y altruismo; estos valores formarán parte de la herencia espiritual-materna que recibirán sus hijas e hijos también. Ya no se trata de la trasmisión de la herencia material-paterna, sino de la espiritual-materna ${ }^{2}$, lo que representa sin duda una amenaza a la frágil estabilidad del orden patriarcal gobernado por valores falsos e hipócritas. Ya antes de Clara hay una protagonista femenina que rompe definitivamente la trasmisión dinástica masculina imponiendo la ley femenina, la ley de las madres: se trata de Nívea, la madre de Clara y la primera feminista de la narrativa de Isabel Allende. Su resistencia al machismo imperante en la sociedad latinoamericana llega a su máxima expresión con el acto simbólico de cortar el álamo, donde los hombres de la familia probaban su valor trepándolo. Poniendo fin al "rito de iniciación" (Allende 1982: 92) peligroso e inútil, Nívea inaugura la línea femenina en el árbol genealógico imponiendo de esa manera el respeto de valores más auténticos y profundos.

La protagonista que desarrolla esta línea haciéndola llegar al punto más alto es Eva Luna. Ella también recibe de su madre la tendencia natural de perderse y navegar en los mares infinitos de la fantasía. Consuelo, otro nombre simbólico, es una mujer sola y pobre que creando con Eva un lazo muy profundo e intimo, transmite a su hija "su sentido particular de la vida" creciéndola desde su infancia con cuentos fantásticos, seres mágicos y objetos animados que empiezan a hacer parte de la vida cotidiana de las dos mujeres. Como las protagonistas de las novelas anteriores y también posteriores, la madre de Eva construye un mundo protegido y separado de la realidad; se trata de una dimensión fantástica construída gracias al poder creativo de las palabras, en la que Eva encontrará fuerza y voluntad para sobrevivir y cambiar las condiciones de su existencia. Consuelo dice a su hija "Las palabras son gratis, decía y se les apropiaba, todas eran suyas. Ella sembró en mi cabeza la idea de que la realidad no es sólo como se percibe en la superficie, también tiene una dimensión mágica y, si a uno se le antoja, es legítimo exagerarla y ponerle color para que el tránsito por esta vida no resulte tan aburrido" (Allende 1987: 28). Cuando Eva se transformará en una mujer madura y determinada dirá, en la colección Cuentos de Eva Luna (1989), "A veces para exorcizar los demonios de un recuerdo es necesario contarlo como un cuento" (Allende 1987: 177). Eva Luna encuentra en el proceso creativo de contar el medio para sobrevivir, suprimir los malos recuerdos, construir una imagen aceptable de su vida y sobre todo encontrarse sí misma, sus deseos y sueños: vivir una existencia libre e independiente ${ }^{3}$.

2 Isabel Allende destruye la estructura familiar tradicional de tipo patriarcal, ofreciendo a las madres la posibilidad de crear al interior de la familia un sistema alternativo, en el que la voz de la mujer desafia los conceptos tradicionales de fertilidad, poder y control.

3 La frontera que separa el mundo real de la dimensión fantástica es por eso muy frágil, lo que nos permite de definir la novela de Eva Luna como la más representativa del realismo mágico. 
Para poder construir una dimensión siguiendo sus propias exigencias, las protagonistas tienen que adquirir un grado de conocimiento de sí mismas muy profundo. Ellas encuentran en los procesos creativos, manuales, mentales y más explícitamente en la escritura los medios a través de los cuales encuentran y conocen la naturaleza más auténtica. Isabel Allende acompaña a sus protagonistas desde un estado de total ignorancia del proprio ser y del contexto en el que viven al principio de las novelas hasta una profunda toma de conciencia de su identidad. El ejemplo más hermoso y completo de maduración espiritual y social está representado por Eva Luna, que pasando por diferentes etapas de aprendizaje y maduración llega al final hasta un mejor auto-análisis de su proprio "ser". En el desarrollo espiritual y social de Eva Luna se van marcando algunas características del Bildungsromán alemán que a diferencia de las novelas de formación latinoamericanas anteriores a la escritora chilena permiten a la protagonista encontrar al final de la novela una dimensión en la que puede definirse como ser humano y sobre todo como mujer completa, libre e independiente. En la trayectoria de Eva Luna están la dura cotidianidad de una mujer de baja clase social, la vida en la calle, el éxito y el lujo, la formación intelectual y la maduración espiritual, la realidad historica y la dictatura, la oposición y las guerrillas, la solidariedad y la amistad, y al final de todo también la realización del amor. Si esta figura femenina representa ya un éxito en el superamiento de las normas impuestas por el riguroso orden moral y social patriarcal, la verdadera victoria feminista está representada según mi opinión por Carmen en El plan infinito (1991), la primera novela con una figura masculina en el rol del personaje central. Isabel Allende se sirve del protagonista masculino para comparar dos diferentes trayectorias de maduración y conocimiento interior. Un hombre de baja clase social tiene más posibilidades y libertades para realizar sus ambiciones. La mujer en cambio tiene que encontrar en sí misma una determinación y una voluntad trasgresora muy fuerte para elevarse de la condición de subordinación y total adhesión a las normas morales. Mientras que el protagonista descubre sólo al final de la novela que la propia identidad se esconde detrás del mito nacional del individuo independiente, orgulloso y líbero (Allende 1991: 225) ${ }^{4}$, ideales fundados en valores hipócritas, artificiales y suoperficiales, la protagonista impone la propia voluntad y sus deseos ya antes de dejar la casa paterna y emprender un largo viaje parecido al de Eva Luna. Carmen, la "zíngara estrafalaria y melenuda" (Allende 1991: 210) crecerá, madurará y llegará a coger de cada experiencia una enseñanza de vida. Ella encontrará en el interior de sí misma la fuerza y la determinación para superar también los tabú sicológicos, logrará hacerse aceptar por el padre que después del aborto prefiere considerarla muerta, tendrá éxito social, profesional y económico y al final completará la propia evolución espiritual enamorándose y volcando todo su amor en el crecimiento de un hijo. La maternidad es lo que Eva Luna no logra realizar en su vida y que hace llegar a Carmen a una grado más alto y completo de la evolución de una mujer.

En efecto el amor representa para Isabel Allende y para sus personajes el eje vital de la existencia de cada ser humano; ya no es la única pasión que absorbe las vidas de las prota-

4 El contexto geográfico y social se traslada al mundo occidental de la California de los años sesenta y no más la America Latina. 
gonistas, como lo fue para las escritoras anteriores; no es el único campo en el que se realizan las mujeres, que encuentran significado también en otros campos. El amor es el sentimiento que las madres transmiten a sus hijas e hijos que tarde o temprano descubrirán la absurdidad de las rigurosas reglas morales impuestas por el sistema patriarcal; el amor es la fuerza que crea entre todos los personajes un vínculo de solidaridad y complicidad. El amor es también la fuerza que impulsa las protagonistas a reaccionar, a buscar sus más íntimos sentimientos y deseos y encontrar un significado también fuera del matrimonio y de la maternidad, las únicas dimensiones en las que se puede mover la mujer. A exclusión de Nivea y Clara en $L a$ casa de los espíritus todas las protagonistas se enamoran de un revolucionario o "outsider" que les hace reflexionar no sólo sobre la condición en la que se encuentran, sino también las introduce en la realidad social y politica de su proprio pais del cual han sido excluídas. De esa manera se le presenta a Isabel Allende la oportunidad de incluir informaciones históricas y políticas que la historiografia oficial prefiere dejarlas escondidas en la sombra.

También en el interior de este discurso el ejemplo de Eva Luna representa la cumbre de la evolución gradual de la conciencia social y politica a la que llegan las protagonistas de las obras anteriores. El personaje que introduce a Eva Luna en el contexto político, especificamente en el mundo de la oposición al régimen dictatorial, es un joven que conoce en la calle y que despierta en ella el enamoramiento adolescente. Impulsada por la fuerza del amor Eva participa activamente en la lucha de la guerilla, donde encuentra también su co-protagonista, cuya historia de vida se desarrolla ya desde el principio de la novela paralelamente a la trayectoria de Eva. Se trata de un fotógrafo que rueda con su telecámara las imágenes que algún día permitirán salir de la sombra la verdadera historia, la versión real de los acontecimientos sociales y políticos. Eva descubre en este personaje al hombre de su vida, que siguiendo su consejo pondrá también su arte al servicio de la causa histórica introduciendo en su folletín televisivo, uno de los mejores medios de penetración cultural y sobre todo una de las pocas formas toleradas por la censura, verdades e informaciones ocultadas o manipuladas por los medios de comunicación oficiales.

Otra protagonista que a través del amor descubre una parte de la realidad antes ignorada es Blanca en La casa de los espiritus. Enamorándose de un cantante popular revolucionario, que resulta ser la personificación de Victor Jara, conoce una parte de la realidad histórica hasta entonces ocultada detrás de una vida de convenciones y comodidades burguesas. Después de ella, la primera mujer que toma posición y reacciona incorporándose a la acción política es su hija Alba. El conocimiento del amor acompaña también aquí el descubrimiento de la realidad política y social de su proprio país. Dejando la posición marginal y el tono ingenuo, introspectivo e intimista de los cuadernos de su abuela Clara, Alba escribe y documenta con voz autoritaria, y no más desde una posición marginal, la vida privada de las mujeres y otros miembros de su familia, en la que penetra gradualmente la historia del país chileno. Irrumpiendo en la esfera pública el texto de Alba se transforma en un acto político y subversivo que descubre y denuncia verdades e injusticias sufridas por los indefensos y emarginados.

La acción rivolucionaria de Alba será continuada por Irene, la protagonista de la novela siguiente De amor y de sombra (1984). Partiendo de una total ignorancia del acontecer 
histórico de su pais y tomando el periodismo como un juego burgués muy interesante y divertido, desarrollará junto al joven fotógrafo revolucionario, que se transformará en su amante, una conciencia social y política muy profunda. El título de la novela sugiere el juego de luces y sombras, que metafóricamente pueden hacer referencia a la iluminación de la conciencia de la protagonista de su propia identidad en un primer momento, y del acontecer social y politico en un segundo. Irene denunciará la brutalidad dictatorial escribiendo la historia del descubrimiento de cuerpos de desaparecidos en la mina de Lonquén.

Trasladándonos en el contexto geográfico californiano durante la época de la Fiebre del oro (siglo XIX), encontramos a otro personaje femenino capaz de romper los moldes culturales y los tabúes sicológicos que caracterizan la rígida sociedad chilena del siglo decimonónico: la protagonista de Hija de la Fortuna (1998), la última novela publicada por Isabel Allende, se separa de las comodidades y lujos de su casa burguesa para seguir y buscar el joven del que se enamora, un revolucionario intelectual que parte impulsado por el deseo de encotrar fortuna y riqueza en California. Dejando el "paraiso" en el que vivió desde su nacimiento, Eliza, asi se llama la protagonista, conoce, madura y aprende vivir en un mundo diferente, donde existe la criminalidad, la injusticia, la pobreza, la competencia, la violencia, el vicio, la insaciabilidad y avidez humana. La dimensión en la que Eliza encuentra ayuda, sensibilidad, solidaridad y sobre todo cariño es el mundo de las prostitutas. La que saca Eva Luna de la calle y le hace aprender la importancia de la dignidad, decencia, instrucción y solidaridad es también una prostituta. Es en este mundo repudiado y condenado por una sociedad aparentemente pura y moral que Eva conoce Melecio-Mimi, el transexual que la educa y la exhorta a narrar regalándole su primera máquina de escribir. El mundo de las prostitutas y de los homosexuales viene representado en la obra de Isabel Allende en una luz positiva denunciando en cambio la corrupción de los potentes y de los militares que escondiéndose detrás de una máscara puritana alimentan el vicio y la corrupción. Las dos realidades se ponen en confrontación cuando en La casa de los espíritus es una prostituta a salvar Alba de la perrera, el campo de concentración en el que el régimen dictatorial ha condenado la joven rebelde.

Isabel Allende ofrece a sus protagonistas infinitas posibilidades de trasformar y modificar las condiciones de su existencia, tomar control de sus propios destinos y desarrollar en un segundo momento una conciencia social y política para poder reivindicar el derecho de ser parte activa de la historia: algunas participan activamente a la vida política de su proprio pais, y otras simplemente ofrecen solidaridad y ayuda a los marginados, perseguidos y a las víctimas de la violencia y represión social. Las protagonistas dignifican así una existencia condenada al silencio, a la resignación, alienación, subordinación y pasividad. Transformándose en personajes activos ellas reaccionan, hablan, cuentan, escriben y luchan por el triunfo de la verdad y de la libertad en general. Ellas se apoderan del lenguaje del cual han sido excluídas para contar, denunciar y testimoniar la existencia de los que junto a ellas han sido marginados, postergados y excluídos de las fuentes históricas tradicionales.

El cuadro que Isabel Allende nos ofrece a través de su obra no se restringe exclusivamente a la problemática padecida por la mujer en la sociedad latinamericana: considerando la experiencia de Eva Luna como ejemplo más completo de la evolución y emancipación de 
la mujer latinoamericana, concluimos que la protagonista disfruta elementos que el sistema patriarcal y machista impone a las mujeres, como por ejemplo la fantasía, la magia, los trabajos domésticos y los folletinos televisivos, inventa y falsifica la realidad adornándola y alterándola a su antojo, transgrediendo de esa manera la lógica del lenguaje falocéntico e insertando en el una profunda crítica social y política. La verdadera dimensión de la mujer que rompe con los estereotipos tradicionales se sitúa así dentro del marco amplio de las luchas colectivas contra las injusticias, los perjuicios, el racismo y la violencia legitimizados por una sociedad falocéntrica.

\section{Bibliografia}

ALLENDE 1987: Allende I., Eva Luna, Barcelona, Plaza \& Janés, 1998.

ALLENDE 1991: Allende I., El plan infinito, Barcelona, Plaza \& Janés, 1998.

GálVEZ-CARuISLe 1991: Gálvez-Carlisle G., "El sabor picaresco en Eva Luna", in Critical Approaches to Isabel

Allende's Novels, Ed. by S. R. Rojas and E. A. Rehbein, New York, Peter Lang, 1991, p. 172.

RoJas \& ReHBeIN 1991: Rojas S. R., Rehbein E.A. (eds.), Critical Approaches to Isabel Allende's Novels, New York, Peter Lang, 1991.

ALLENDE I., La casa de los espiritus, Barcelona, Plaza \& Janés, 1999.

ALLENDE I., De amor y de sombra, Barcelona, Plaza \& Janés, 1999.

AlLENDE I., Cuentos de Eva Luna, Barcelona, Plaza \& Janés, 1997.

ALLENDE I., Afrodita, Barcelona, Plaza \& Janés, 1999.

ALlENDE I., Hija de la fortuna, Barcelona, Plaza \& Janés, 1999.

\section{ISABEL ALLENDE ALI MORFOLOGIJA ŽENSKIH GLASOV}

Ustvarjalni navdih čilske pisateljice Isabel Allende ozivlja podobe tistih, ki jih je južnoameriška zgodovina (sad nestetih diktatur in nečloveških družbenih vrednot) potisnila v pozabo. Njeni romani pa so pravi hommage vsem ženskam, ki s svojim pogumom in ljubeznijo zahtevajo, da jim uradna zgodovina prizna obstoj v vsakdanjem družbeno-političnem dogajanju. Življenjska izkušnja mlade Eve Lune predstavlja najpopolnejši primer odkrivanja ženske intimnosti, nepriznanih nagonov in najskritejših sanj. Do zmage nad napravičnostjo in krutostjo južnoameriške patriarhalno-mačistične družbe jo spremljajo pristnost, trdnost, odločnost in samozavest. $\mathrm{V}$ romanih čilske pisateljice zaživi bogat zaklad ženskih likov, katerih življenjske izkušnje lahko primerjamo $\mathrm{z}$ avtobiografijo Eve Lune. Isabel Allende ustvarja tako magično realistično literaturo, ki z izrazitim čutom za fantastičnost črpa iz vsakdanje južnoameriške problematike. 